Original Article

\title{
ANALYTICAL METHOD DEVELOPMENT AND VALIDATION FOR SIMULTANEOUS ESTIMATION OF CURCUMIN AND CYCLOSPORINE BY RP-HPLC
}

\author{
NEHA DESAI ${ }^{*}$, MUNIRA MOMIN $^{1}$, UPASANA SINGH ${ }^{2}$, TABASSUM KHAN $^{3}$, ATUL SHERJE $^{3}$
}

${ }^{1}$ Department of Pharmaceutics, SVKM's Dr. Bhanuben Nanavati College of Pharmacy, Vile Parle (W), Mumbai 400056, Maharashtra, India, 2Junior Research Associate Formulation Development, Indoco Remedies Limited, Thane, Mumbai 400701, Maharashtra, India, ${ }^{3}$ Department of Quality Assurance, SVKM's Dr. Bhanuben Nanavati College of Pharmacy, Vile Parle (W), Mumbai 400056, Maharashtra, India

Email: nihadesai27@gmail.com

Received: 06 Aug 2018 Revised and Accepted: 20 Dec 2018

\section{ABSTRACT}

Objective: The present work was undertaken with an aim to develop and validate a rapid reverse-phase high-performance liquid chromatography (RP-HPLC) method for the estimation of curcumin and cyclosporine in the capsule dosage form.

Methods: The RP-HPLC method for the simultaneous estimation of curcumin and cyclosporine was developed using Agilent (Infinity 1260) HPLC system and Eclipse XDB-C18 (4.6 x $150 \mathrm{~mm}$ i.d., $5 \mu$ ) stationary phase. The optimized mobile phase comprised of acetonitrile: water: methanol (50: $10: 40 \mathrm{v} / \mathrm{v} / \mathrm{v}$ ) pumped at a flow rate of $0.5 \mathrm{ml} / \mathrm{min}$. Separation of drugs was achieved in an isocratic mode and elution was monitored using PDA detector at $214 \mathrm{~nm}$. The method was validated as per ICH-Q2R1 guidelines.

Results: Retention time of the curcumin and cyclosporine were found to be $3.073 \mathrm{~min}$ and $6.373 \mathrm{~min}$ with the correlation coefficient $\left(\mathrm{R}^{2}\right)$ of 0.9993 and 0.998 respectively. The response of curcumin and cyclosporine was found linear in the concentration range of 8-48 $\mu \mathrm{g} / \mathrm{ml}$ and $4-24 \mu \mathrm{g} / \mathrm{ml}$ respectively. The percent recovery values were found in the range of $97-103 \%$ indicating satisfactory accuracy of the method. The percent relative standard deviation (\% RSD) values for the precision study was less than 2 which suggest that the method is precise.

Conclusion: The proposed method was found accurate, precise and specific for the determination of curcumin and cyclosporine in bulk as well as in capsule dosage form. Thus, the present method can be used for routine analysis and quality control of curcumin and cyclosporine in bulk and capsule dosage form.

Keywords: Curcumin, Cyclosporine, ICH Guidelines, RP-HPLC

(C) 2019 The Authors. Published by Innovare Academic Sciences Pvt Ltd. This is an open access article under the CC BY license (http://creativecommons.org/licenses/by/4.0/) DOI: http://dx.doi.org/10.22159/ijpps.2019v11i2.28975

\section{INTRODUCTION}

Chemically, curcumin is (1E, 6E)-1,7-bis (4-hydroxy-3-methoxyphenyl)1,6-heptadiene-3,5-dione [1]. Literature survey revealed LC-MS [2], RPHPLC [2], HPTLC [3], stability indicating HPLC [4], and UV spectrophotometric [1,5-7] methods for estimation of curcumin alone or in combination with other drugs in bulk, in dosage forms and human plasma. Cyclosporine is an immunosuppressant drug used in post allogenic organ transplant to reduce the activity of patient's immune system. Chemically it is (3S,6S,9S,12R,15S,18S,21S,24S,30S,33S)-30ethyl-33-[(E,1R,2R)-1-hydroxy-2-methylhex-4-enyl]-1,4,7,10,12,15,19, 25,28-nonamethyl-6,9,18,24-tetrakis (2-methylpropyl)-3,21-di (propan2-yl)-1,4,7,10,13,16,19,22,25,28,31-undecazacyclotritriacontane-2,5,8, $11,14,17,20,23,26,29,32$-undecone [8]. Several bioanalytical methods which include RP-HPLC [8], LC-MS [8] and RP-HPLC [8] were also reported for the analysis of cyclosporine in soft gelatin capsule dosage [5]. The molecular structures of curcumin and cyclosporine is given in fig. 1.<smiles>COc1cc(/C=C/C(=O)CC(=O)/C=C/c2ccc(O)c(OC)c2)ccc1O</smiles>

(a)

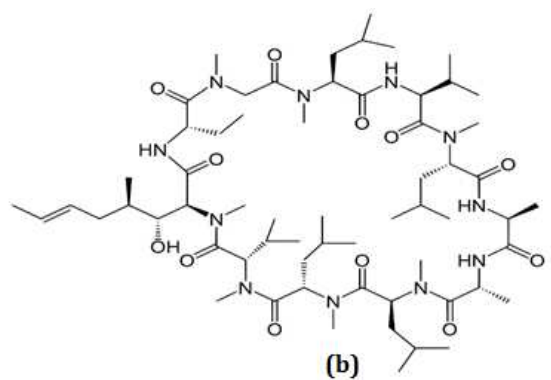

(b)

Fig. 1: Molecular structure of (a) curcumin and (b) cyclosporine

Till date, RP-HPLC method was not developed for the simultaneous estimation of curcumin and cyclosporine in the pharmaceutical dosage form. Therefore, the present study was attempted to develop a simple, accurate, precise and specific RP-HPLC method for quantitative determination of curcumin and cyclosporine in capsule dosage form for management of inflammatory bowel disorder (IBD).
There is no marketed formulation of curcumin and cyclosporine (pellets in a capsule or any other pharmaceutical dosage form) for the management of IBD. The literature states that curcumin and cyclosporine, when used in combination, can successfully manage the remission of ulcerative colitis [9]. Therefore, a fixed-dose combination capsule formulation containing bioadhesive pellets of 
curcumin and cyclosporine was developed in-house. The developed and optimized formulation of bioadhesive pellets containing curcumin and cyclosporine was selected for in vitro drug release study.

\section{MATERIALS AND METHODS}

Curcumin and cyclosporine were procured from Otto Chemie Pvt. Ltd., Mumbai, India and Concord Biotech Limited Ahmedabad, India respectively. HPLC grade acetonitrile and methanol were procured from SD Fine Chemical Ltd., Mumbai, India. Millipore water was used for the preparation of chemicals/solutions.

\section{HPLC instrumentation and chromatographic conditions}

Analytical chromatography was performed on a Agilent HPLC system (Infinity 1260) equipped with auto-sampler and photo diode array (PDA) detector. Chromatographic separation of curcumin and cyclosporine was achieved on Eclipse XDB-C18 (4.6 x $150 \mathrm{~mm}, 5 \mu$ particle size) column at a temperature of $70{ }^{\circ} \mathrm{C} \pm 0.02{ }^{\circ} \mathrm{C}$. The mobile phase comprised of acetonitrile: water: methanol (50:10:40 v/v/v). The flow rate was at $0.5 \mathrm{ml} / \mathrm{min}$., drug peaks were detected at 214 $\mathrm{nm}$ with an injection volume of $20 \mu \mathrm{l}$.

\section{Preparation of standard solutions}

\section{Preparation of stock solution}

Stock solutions were prepared by dissolving $10 \mathrm{mg}$ of curcumin and $10 \mathrm{mg}$ of cyclosporine in $10 \mathrm{ml}$ of methanol separately and subjected to sonication to give an individual concentration of $1000 \mu \mathrm{g} / \mathrm{ml}$.

\section{Method development}

Aliquots of the standard stock solutions were further diluted with mobile phase to get $24 \mu \mathrm{g} / \mathrm{ml}$ of curcumin and $12 \mu \mathrm{g} / \mathrm{ml}$ of cyclosporine. The samples were injected in the HPLC system and chromatograms were recorded. Various combinations of mobile phase components, column temperature, and columns were tried to get desirable resolved peaks.

\section{Method validation}

\section{System suitability}

The system suitability test is used to verify that the chromatographic system is suitable for the intended analysis or not. The system suitability of the method was checked by injecting six different injections of $24 \mu \mathrm{g} / \mathrm{ml}$ of curcumin and $12 \mu \mathrm{g} / \mathrm{ml}$ of cyclosporine. Various parameters like tailing factor, theoretical plates, peak area and resolution were checked according to USP criteria $[10,11]$.

\section{Specificity}

Specificity is the ability to measure accurately and specifically the analyte of interest in the presence of other components that may be expected to be present in the sample matrix. Specificity was carried by dissolving $500 \mathrm{mg}$ of placebo sample (pellets made up of excipients viz. avicel PH 101, carbopol 940, hydroxypropyl cellulose-H and sodium chloride excluding both the drugs) in $100 \mathrm{ml}$ of mobile phase.

\section{Precision}

Precision was studied at three levels: repeatability, intermediate precision, and reproducibility.

Repeatability: Repeatability study was performed by preparing a minimum of six determinations $(n=6)$ of test concentration (curcumin $24 \mu \mathrm{g} / \mathrm{ml}$ : cyclosporine $12 \mu \mathrm{g} / \mathrm{ml}$ ) and was analyzed. It is expressed as the percent relative standard deviation (\% RSD).

Intermediate Precision: The extent to which intermediate precision should be established depends on the circumstances under which the procedure is intended to be used. This study was done at two levels (intra-day and inter-day study). Intra-day precision was done by preparing the test concentration (curcumin $24 \mu \mathrm{g} / \mathrm{ml}$ and cyclosporine $12 \mu \mathrm{g} / \mathrm{ml}$ ) and assaying for six times $(\mathrm{n}=6)$ at 3 different time intervals. Inter-day precision was done by analyzing samples $(n=6)$ for three consecutive days. The percent relative standard deviation (\% RSD) values were calculated.

\section{Accuracy}

This study was carried out by spiking standard solution of curcumin and cyclosporine to the placebo. Placebo was prepared containing avicel PH 101, carbopol 940, hydroxypropyl cellulose-H and sodium chloride which were further coated with Eudragit S100 as enteric coating polymer using isopropyl alcohol and acetone in the ratio of $1: 1$ [12-15]. This placebo batch was selected for the accuracy studies since marketed formulation containing both the drugs was not available. Concentrations of curcumin and cyclosporine corresponding to $80 \%, 100 \%$, and $120 \%$ were added to $1 \mathrm{ml}$ solution of pre-analyzed placebo formulation and percent recovery of drug-spiked was determined. The study was performed in triplicates and mean \% RSD was determined.

\section{Linearity and range}

The linearity of an analytical procedure is its ability (within a given range) to obtain test results which are directly proportional to the concentration (amount) of analyte in the sample. It is generally reported as the variance of slope or regression line. A range is an interval between the upper and lower concentrations of solute that have been demonstrated to be determined with precision, accuracy, and linearity. To establish the linearity of this method 8-48 $\mu \mathrm{g} / \mathrm{ml}$ for curcumin and 4$24 \mu \mathrm{g} / \mathrm{ml}$ for cyclosporine was prepared from the stock solution and analysed. Each concentration measurement was performed in triplicate. Peak areas were plotted versus respective concentrations and linear regression analysis was performed on the resultant curves.

\section{LOD and LOQ}

Limit of detection (LOD) and limit of quantification (LOQ) decide the sensitivity of the method. LOD is the lowest detectable concentration of the analyte by the method while LOQ is the minimum quantifiable concentration. ICH defines the detection limit of an individual analytical procedure as the lowest amount of analyte in a sample which can be detected but not necessarily quantitated as an exact value. The LOD is the point at which a measured value is larger than the uncertainty associated with it. The quantitation limit is a parameter of quantitative assays for low levels of compounds in sample matrices and is used particularly for the determination of impurities or degradation products. LOD and LOQ were calculated from standard calibration curves of drugs using following equations-

$$
\text { Limit of detection (LOD) } \frac{3.3 \times \sigma}{\text { Slope }}
$$

Where $\sigma$ is standard deviation and slope of the calibration curve of respective drug.

$$
\text { Limit of quantification (LOQ) } \frac{10 \times \sigma}{\text { Slope }}
$$

\section{Robustness}

The robustness of an analytical procedure is a measure of its capacity to remain unaffected by small but deliberate variations in method parameters and provides an indication of its reliability during its normal usage. The test concentration of curcumin and cyclosporine (curcumin $24 \mu \mathrm{g} / \mathrm{ml}$ and cyclosporine $12 \mu \mathrm{g} / \mathrm{ml}$ ) were injected by changing the chromatographic conditions. Following changes were made to check the reliability of the method. The study was performed in triplicate.

Variation of flow rate: The chromatographic responses were recorded by a change in the flow rate to $0.4 \mathrm{ml} / \mathrm{min}$ to $0.6 \mathrm{ml} / \mathrm{min}$.

Variation in temperature: The chromatograms of curcumin and cyclosporine was measured by a change in the temperature to $69^{\circ} \mathrm{C}$ to $71^{\circ} \mathrm{C}$.

\section{Drug content}

The bioadhesive pellets were triturated using mortar and pestle and the powder blend equivalent to $30 \mathrm{mg}$ of drug (curcumin $20 \mathrm{mg}$ and cyclosporine $10 \mathrm{mg}$ ) was dispersed in $10 \mathrm{ml}$ of distilled water in 10 $\mathrm{ml}$ amber colored volumetric flask. The resultant dispersion was filtered after an appropriate interval of time (for the drug to come 
into the medium) to give a clear solution. An aliquot of $1 \mathrm{ml}$ was withdrawn from this solution and diluted up to $10 \mathrm{ml}$. The percent of drug content was determined.

\section{In vitro dissolution study}

The in vitro release of drug from the bioadhesive pellets was investigated using USP Type 1 dissolution test apparatus (Basket type, Electrolab) at a rotational speed of $100 \mathrm{rpm} .500 \mathrm{mg}$ of pellets in size 0 hard gelatin capsule shell equivalent to $30 \mathrm{mg}$ of drug was placed in the basket. The apparatus was maintained at $37^{\circ} \mathrm{C} \pm 0.5^{\circ} \mathrm{C}$. The dissolution was carried out in $250 \mathrm{ml}$ of $0.1 \mathrm{~N} \mathrm{HCl}$ with $2 \%$ SLS for $2 \mathrm{~h}$ followed by $250 \mathrm{ml}$ of phosphate buffer ( $\mathrm{pH} \mathrm{6.8)} \mathrm{with} 2 \%$ SLS for additional $4 \mathrm{~h}$ followed by phosphate buffer 7.4 with $2 \%$ SLS for additional $18 \mathrm{~h}$. Aliquot (5 ml) was withdrawn from the dissolution apparatus at specific time intervals of $1,2,3,4,5,6,7,8,9,10$ and 24 $\mathrm{h}$, filtered through 0.45 -micron syringe filter and analyzed using RPHPLC. Sink conditions were maintained by replenishing the same amount of medium. The study was performed in triplicate $(\mathrm{n}=3)$.

\section{RESULTS AND DISCUSSION}

\section{Optimization of chromatographic conditions}

A mobile phase composition of acetonitrile: water: methanol $(50: 10: 40 \mathrm{v} / \mathrm{v} / \mathrm{v} /)$ at a flow rate was at $0.5 \mathrm{ml} / \mathrm{min}$ and Eclipse XDB$\mathrm{C} 18(4.6 \times 150 \mathrm{~mm}, 5 \mu)$ column maintained at $70^{\circ} \mathrm{C} \pm 0.02{ }^{\circ} \mathrm{C}$ were found optimum for to get reproducible peaks with symmetry with limits. The optimized chromatogram of standard curcumin and cyclosporine $(100 \mu \mathrm{g} / \mathrm{ml})$ is given in fig. 2 .

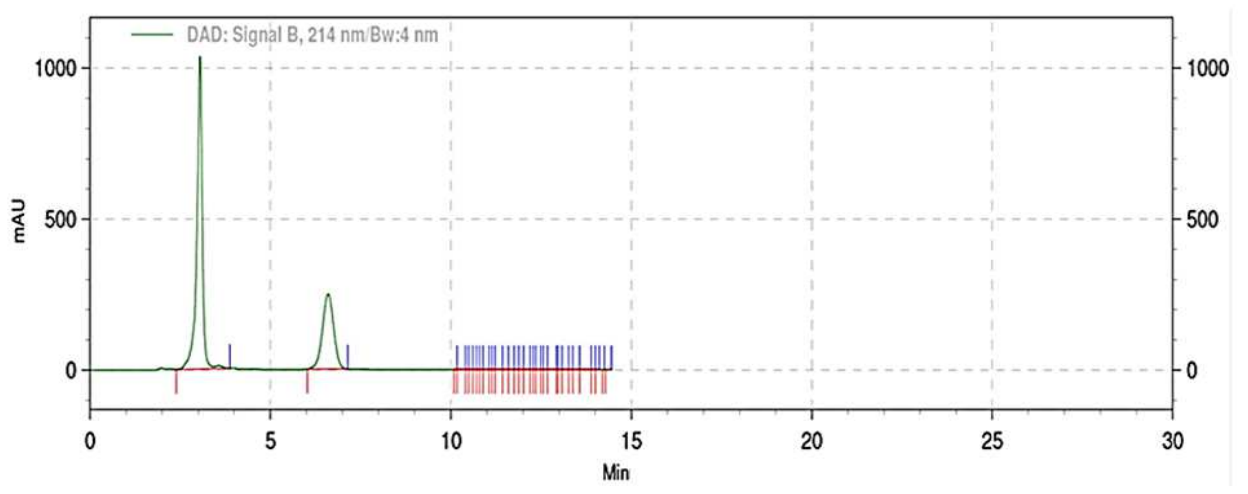

Fig. 2: Chromatogram of standard curcumin and cyclosporine in optimized chromatographic conditions

\section{System suitability}

The system suitability parameters like tailing factor were found to be less than 2 , theoretical plates were not less than 2000 and resolution was found to be more than 2 . All the parameters were fulfilled as per USP acceptance criteria.

The results of system suitability are expressed in table 1.

Table 1: Results of system suitability parameters for curcumin and cyclosporine

\begin{tabular}{llll}
\hline Parameters & Curcumin & Cyclosporine & Acceptance criteria \\
\hline Retention time & $3.047 \pm 0.05$ & $6.587 \pm 0.01$ & -- \\
Resolution & $9.874 \pm 0.01$ & & Rs $>2$ \\
No. of theoretical Plates & $2874 \pm 0.06$ & $2589 \pm 0.04$ & $\mathrm{~N}>2000$ \\
Tailing Factor & $0.764 \pm 0.02$ & $0.981 \pm 0.01$ & $\mathrm{~T}<1.5$ \\
Peak area & $63838533 \pm 218$ & $1368407 \pm 4291$ & -- \\
\hline
\end{tabular}

${ }^{*}$ The data is expressed as mean $\pm \mathrm{SD},{ }^{*}$ n: 6 i.e. number of injections, ${ }^{*} \mathrm{SD}$ : standard deviation

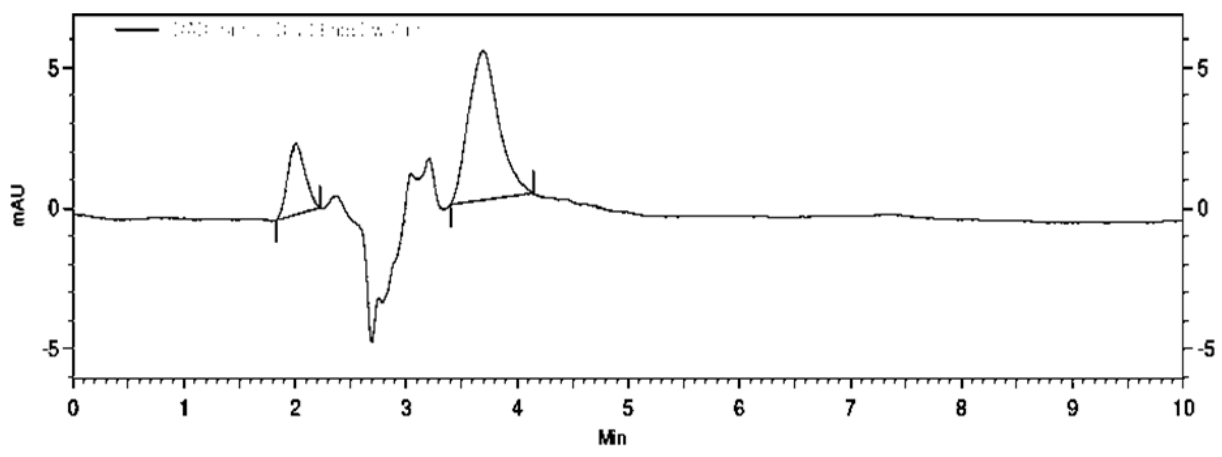

Fig. 3: HPLC chromatogram of placebo (pellets of excipients dissolved in mobile phase)

\section{Specificity}

The optimized method was found to be specific as there was no interference of the mobile phase at the retention time of both the drugs. Chromatogram indicating the specificity of the method is shown in fig. 3 .

\section{Precision}

Repeatability studies, intraday precision, and inter-day precision studies were performed for curcumin and cyclosporine and the $\%$ RSD values were found to be $<2 \%$ for both the drugs. Thus, the 
Table 2: Results of the precision study

\begin{tabular}{|c|c|c|c|}
\hline Precision parameters & & Curcumin & Cyclosporine \\
\hline \multirow[t]{2}{*}{ Repeatability } & Peak area & $6408248 \pm 5849$ & $1357613 \pm 1463$ \\
\hline & $\%$ RSD & 0.9128 & 1.0782 \\
\hline \multirow{5}{*}{$\begin{array}{l}\text { Intraday study } \\
(n=6)\end{array}$} & Peak area: Time 1 & 6414627 & 1355923 \\
\hline & Peak area: Time 2 & 6454088 & 1345019 \\
\hline & Peak area: Time 3 & 6434833 & 1345788 \\
\hline & Pooled mean \pm SD of three-time points & $6434516 \pm 17649$ & $1348910 \pm 5443$ \\
\hline & $\%$ RSD & 0.2742 & 0.4035 \\
\hline \multirow{5}{*}{$\begin{array}{l}\text { Interday study } \\
(n=6)\end{array}$} & Peak area: Day 1 & 6391294 & 1351098 \\
\hline & Peak area: Day 2 & 1352103 & 1352103 \\
\hline & Peak area: Day 3 & 1362419 & 1362419 \\
\hline & Pooled mean \pm SD of three days & $6424627 \pm 288$ & $1355206 \pm 626$ \\
\hline & $\%$ RSD & 0.44931 & 0.4624 \\
\hline
\end{tabular}

${ }^{*}$ The data is expressed as mean $\pm \mathrm{SD},{ }^{*}$ n: 6 i.e. number of injections, ${ }^{*} \mathrm{SD}$ : standard deviation, $* \%$ RSD: percentage relative standard deviation

\section{Accuracy}

The mean recovery for curcumin and cyclosporine was calculated at three different levels. The percentage recovery was found to be between $97-103 \%$ for all three-level and \% RSD were found to be less than 2. The results obtained for recovery at $80 \%, 100 \%$, and $120 \%$ was found to be within the specified limits.

Hence the method was found to be accurate. Results for accuracy are expressed in table 3 and chromatograms are given in fig. 4 .

Table 3: Accuracy studies for curcumin and cyclosporine

\begin{tabular}{|c|c|c|c|c|c|}
\hline & Level & Amount added $(\mathrm{mg} / \mathrm{ml})$ & Amount found (mg/ml) & $\%$ recovery & \%RSD \\
\hline \multirow{3}{*}{ Curcumin } & $80 \%$ & 19.2 & 19.298 & $100.67 \% \pm 0.0020$ & 0.2067 \\
\hline & 100 & 24 & 24.04 & $100.09 \% \pm 0.0009$ & 0.09283 \\
\hline & $120 \%$ & 28.8 & 28.58 & $99.73 \% \pm 0.0075$ & 0.7592 \\
\hline \multirow[t]{3}{*}{ Cyclosporine } & $80 \%$ & 9.6 & 11.93 & $100.39 \% \pm 0.0058$ & 0.5862 \\
\hline & 100 & 12 & 11.92 & $99.50 \% \pm 0.0017$ & 0.1011 \\
\hline & $120 \%$ & 14.4 & 14.43 & $100.13 \% \pm 0.0005$ & 0.05765 \\
\hline
\end{tabular}

${ }^{*}$ The data is expressed as mean $\pm \mathrm{SD},{ }^{*}$ : 3 i.e. number of injections, *SD: standard deviation, ${ }^{*} \% \mathrm{RSD}$ : percentage relative standard deviation

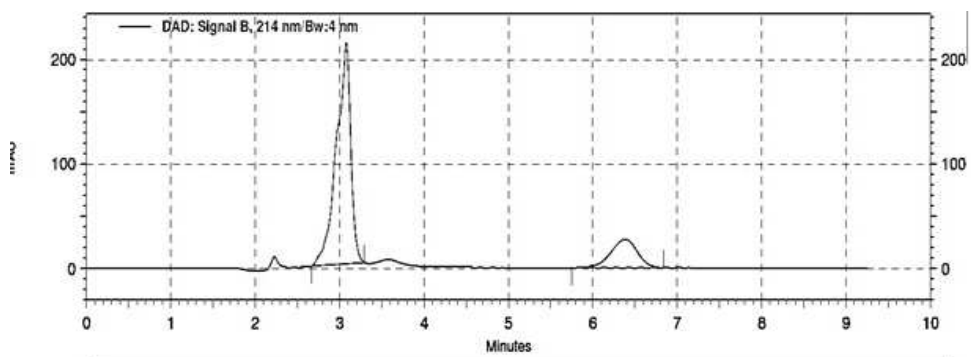

a

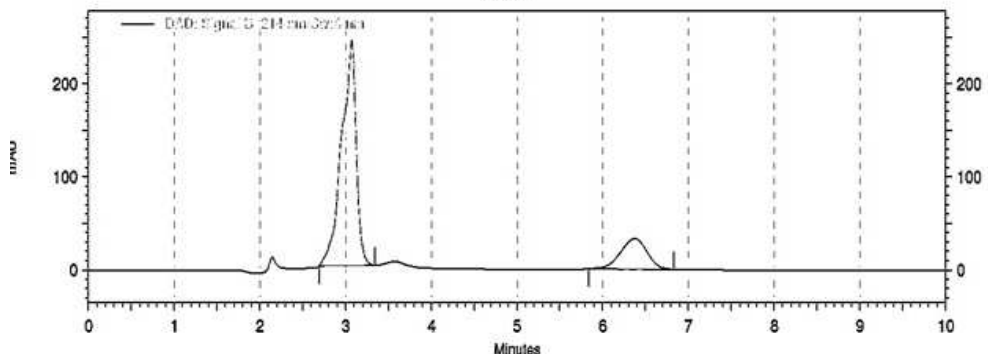

b

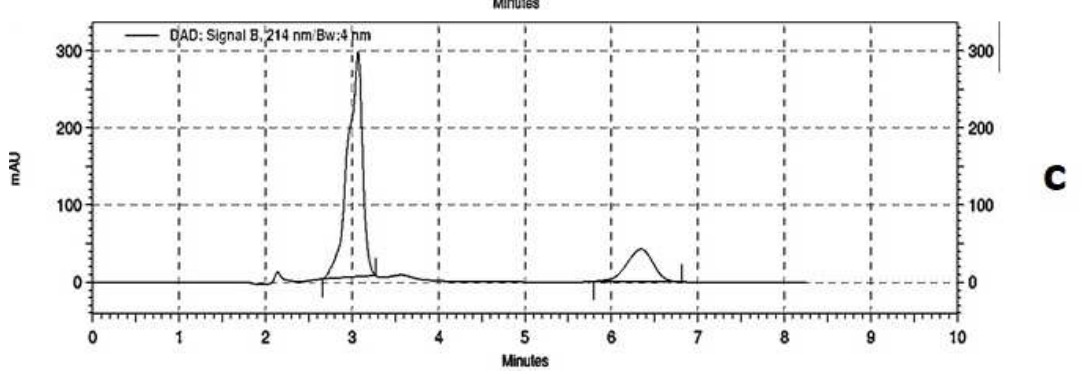

Fig. 4: Chromatogram of curcumin and cyclosporine in accuracy studies at (a) Level 1: 80\%, (b) Level 2: 100\% and (c) Level 3: 120\% 


\section{Linearity and range}

In order to test the linearity of the method, six dilutions of the working standard solutions for the drugs curcumin and cyclosporine in the range of $8-48 \mu \mathrm{g} / \mathrm{ml}$ and $4-24 \mu \mathrm{g} / \mathrm{ml}$ were prepared. Each of the dilutions was injected for the three times $(n=3)$ into the column. Correlation coefficient $\left(\mathrm{R}^{2}\right)$ should be above 0.99 for both the drugs. The correlation coefficients ( $\mathrm{R}^{2}$ value) of developed method for both the drugs were found to be within specified limits. Linearity curves are is depicted in fig. 5 and chromatogram for linearity are shown in fig. 6.
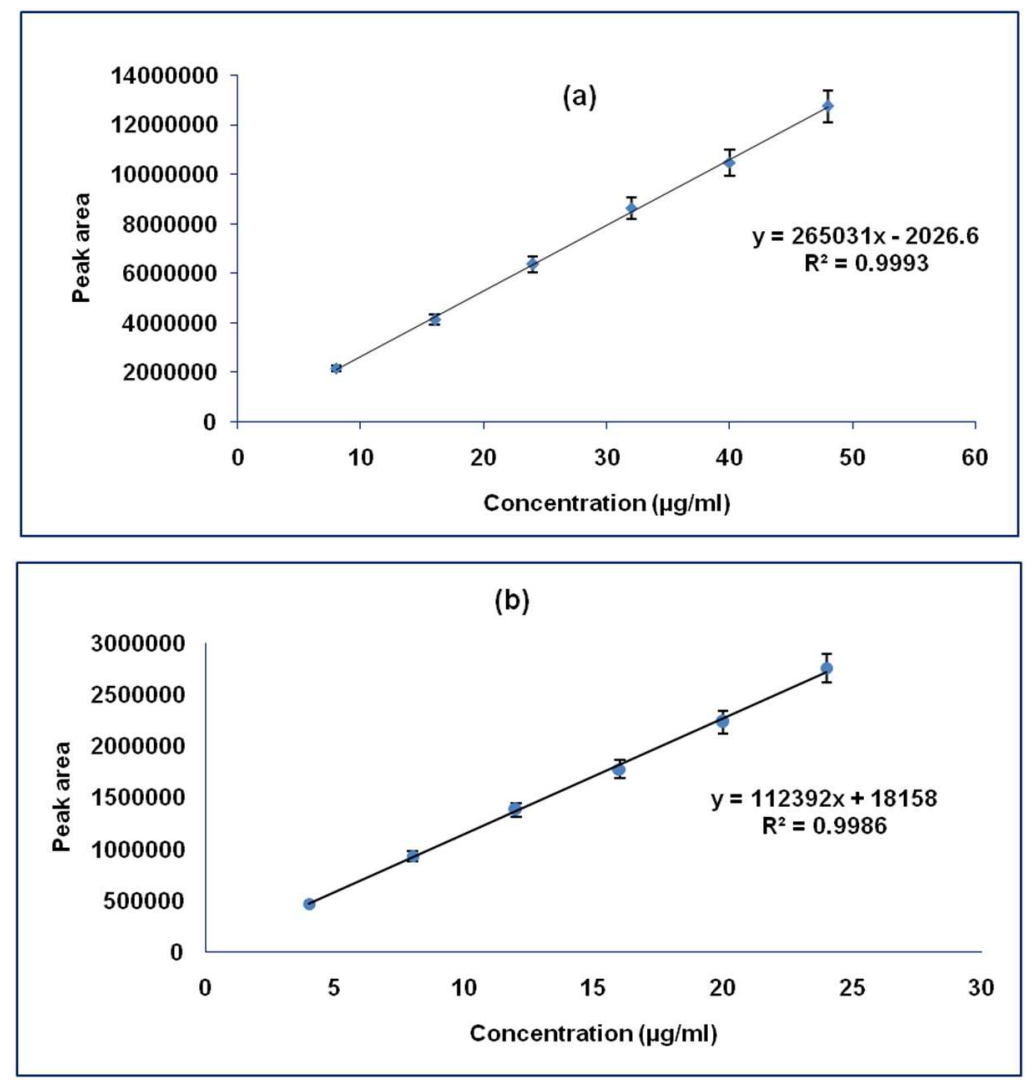

Fig. 5: Linearity curve of (a) curcumin and (b) cyclosporine, (*n: 3 i.e. number of injections of each concentration. The data is expressed in graph as mean \pm SD, *SD: standard deviation)

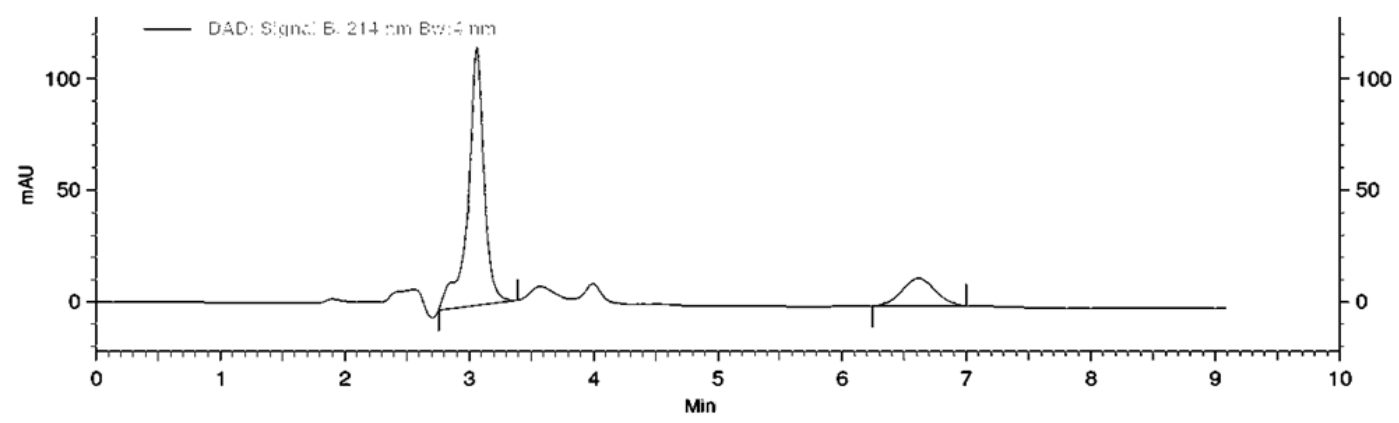

(a)

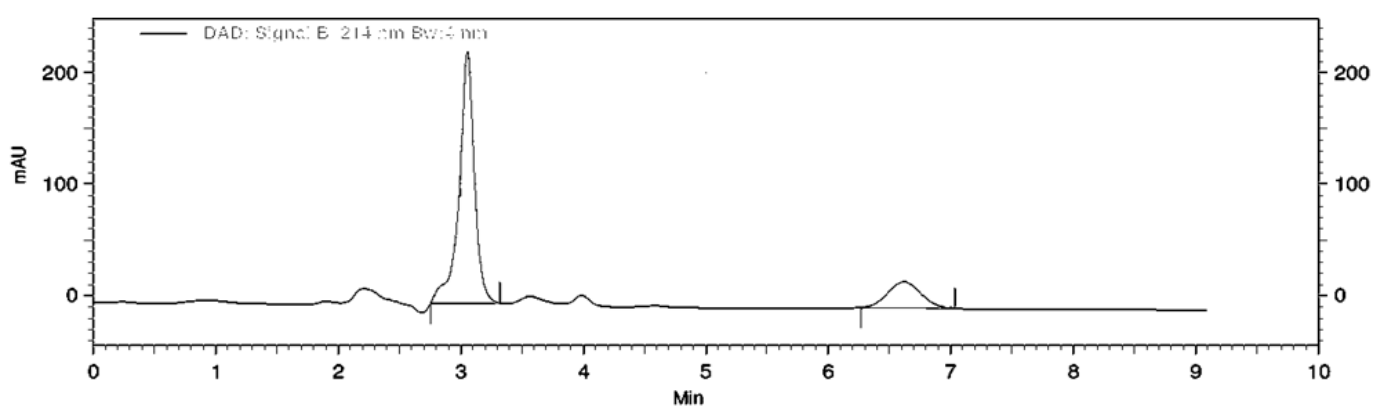

(b) 


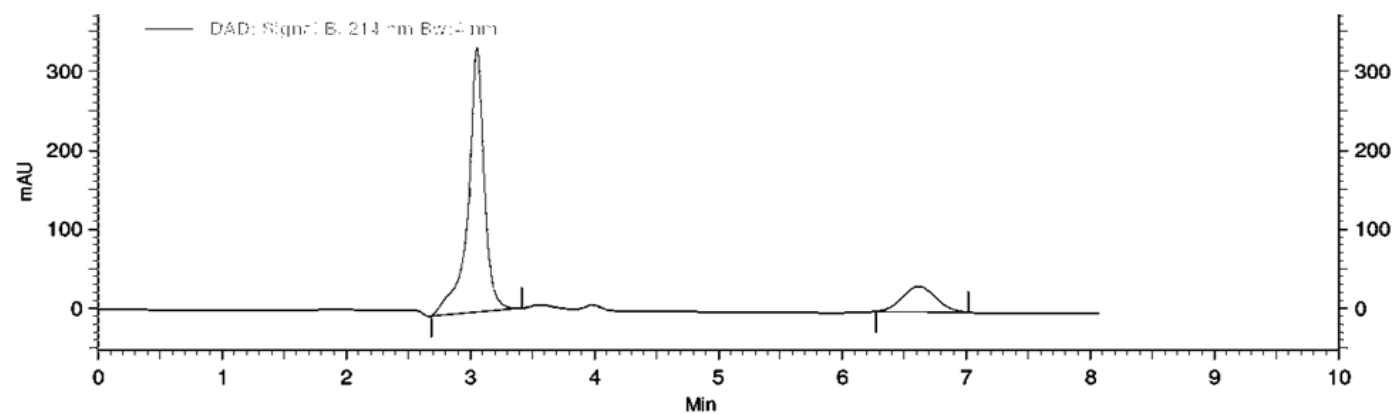

(c)

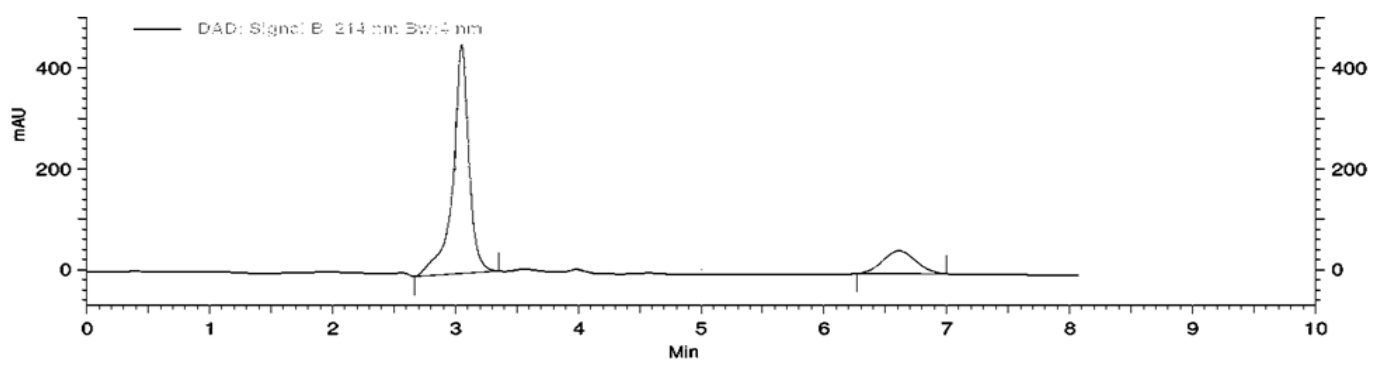

(d)

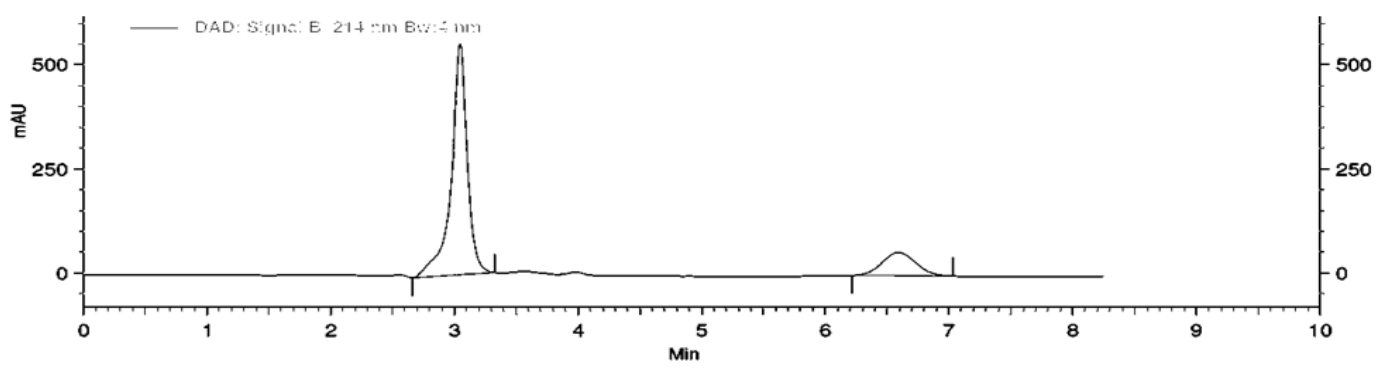

(e)

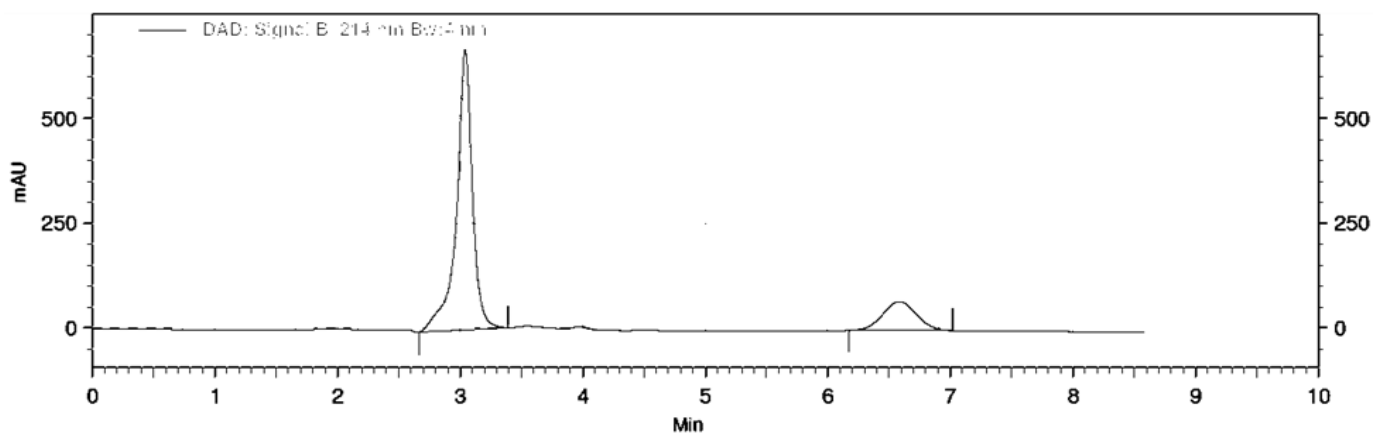

(f)

Fig. 6: Linearity study chromatogram of (a) curcumin $8 \mu \mathrm{g} / \mathrm{ml}$ and cyclosporine $4 \mu \mathrm{g} / \mathrm{ml}$, (b) curcumin $16 \mu \mathrm{g} / \mathrm{ml}$ and cyclosporine $8 \mu \mathrm{g} / \mathrm{ml}$, (c) curcumin $24 \mu \mathrm{g} / \mathrm{ml}$ and cyclosporine $12 \mu \mathrm{g} / \mathrm{ml}$, (d) curcumin $32 \mu \mathrm{g} / \mathrm{ml}$ and cyclosporine $16 \mu \mathrm{g} / \mathrm{ml}$, (e) curcumin $40 \mu \mathrm{g} / \mathrm{ml}$ and cyclosporine $20 \mu \mathrm{g} / \mathrm{ml}$, and (f) curcumin $48 \mu \mathrm{g} / \mathrm{ml}$ and cyclosporine $24 \mu \mathrm{g} / \mathrm{ml}$

\section{LOD and LOQ}

On the basis of peak response and slope of the regression equation, LOD and LOQ was calculated. The LOD of curcumin and cyclosporine was found to be $0.3594 \mu \mathrm{g} / \mathrm{ml}$ and $0.1839 \mu \mathrm{g} / \mathrm{ml}$ respectively. The LOQ of curcumin and cyclosporine was found to be $1.0892 \mu \mathrm{g} / \mathrm{ml}$ and $0.5575 \mu \mathrm{g} / \mathrm{ml}$ respectively.

\section{Robustness}

The method was found to be robust enough that the peak area was not apparently affected by small variation in the chromatographic conditions. On the evaluation of the results, it was concluded that the variation in the flow rate and variation in the temperature does not affect the method significantly. Hence, it was indicated that the method was robust even by a change in these two parameters. The system suitability parameters were within the limits and results for robustness is shown in table 4 .

\section{Drug content}

Drug content of the formulation was found to be $97.34 \pm 0.5 \%$ for curcumin and $95.68 \pm 0.63 \%$ for cyclosporine. Hence it complies with the Pharmacopoeial limit of assay of drugs (90\%-110\%). 
Table 4: Robustness study by varying flow rate and temperature

\begin{tabular}{lllll}
\hline & & Curcumin & \multicolumn{2}{c}{ Cyclosporine } \\
\hline Variable & Level ( \pm ) & Mean Retention time (min) \pm SD & \% RSD & Mean Retention time (min) \pm SD \\
\hline Flow rate $(\mathrm{ml})$ & $0.4 \mathrm{ml}$ & $3.14 \pm 0.005$ & 0.184 & $6.61 \pm 0.005$ \\
& $0.6 \mathrm{ml}$ & $2.9 \pm 0.005$ & 0.199 & $6.55 \pm 0.005$ \\
Temperature $\left({ }^{\circ} \mathrm{C}\right)$ & $69^{\circ} \mathrm{C}$ & $3.043 \pm 0.001$ & 0.056 & $6.58 \pm 0.005$ \\
& $71^{\circ} \mathrm{C}$ & $3.04 \pm 0.0005$ & 0.018 & $6.60 \pm 0.005$ \\
\hline
\end{tabular}

${ }^{*}$ The data is expressed as mean $\pm \mathrm{SD}$, *n: 3 i.e. number of injections at each level, *SD: standard deviation, *\%RSD: percentage relative standard deviation

\section{In vitro dissolution study}

In vitro dissolution studies were performed $20 \%$ weight gain of pellets after coating with Eudragit S100. Curcumin and cyclosporine showed better drug release at $20 \%$ weight gain of pellets after coating with $\mathrm{pH}$-sensitive polymer Eudragit S100. The in vitro dissolution profile of curcumin and cyclosporine in capsule formulation estimated using developed HPLC method is shown in fig. 7. During the acidic stage (gastric stage), cyclosporine and curcumin did not show any release at the end of $2 \mathrm{~h}$. At the buffer stage (Intestinal stage), less than 15\% release of both the drugs was observed at the end of $6 \mathrm{~h}$. At the end of $24 \mathrm{~h}$, almost $80 \%$ of curcumin and cyclosporine was released which was desirable. Thus, the developed HPLC method was successfully applied for the determination of drug release of curcumin and cyclosporine from the capsule dosage form in a dissolution study.

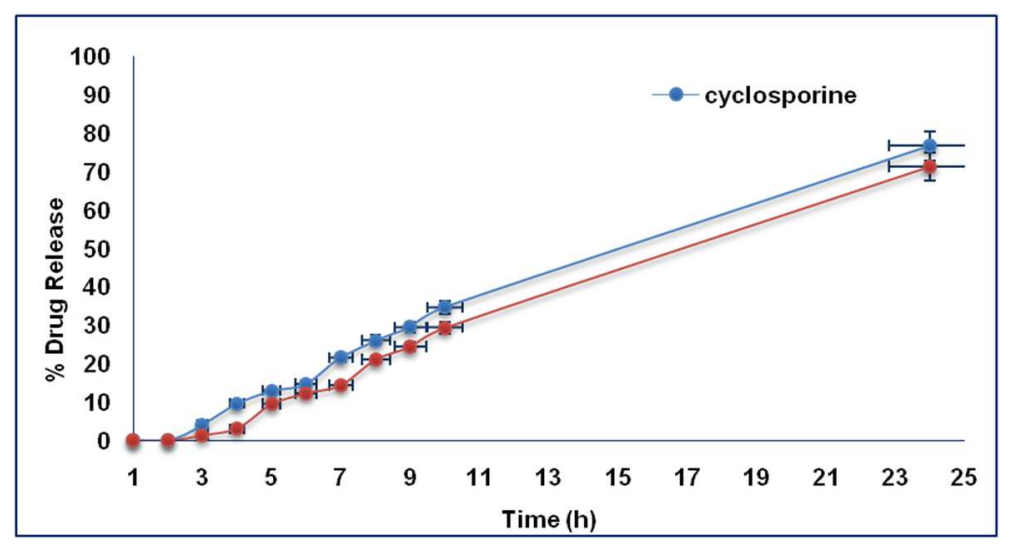

Fig. 7: In vitro drug release study of curcumin and cyclosporine in a capsule formulation using developed RP-HPLC method ( ${ }^{*}$ n: 3 i.e. no. of capsule formulation tested at each time interval. The data is expressed in graph as mean \pm SD, *SD: standard deviation)

\section{DISCUSSION}

A novel, rapid and reproducible RP-HPLC method for simultaneous estimation of curcumin and cyclosporine in capsule dosage form has been developed and validated as per ICH Guidelines. The validation acceptance criteria were satisfied in all cases as per USP/ICH guidelines. Application of this method for estimation of curcumin and cyclosporine from capsule dosage form showed that the excipients did not interfere in the estimation of both the drugs. Hence, this method was specific. The sample recoveries in the formulation were in good agreement and they suggested noninterference of formulation excipients in the estimation. The results obtained from the above set of observations prove that the present RP-HPLC method developed for the quantitative determination of curcumin and cyclosporine in the formulation was simple, sensitive, accurate, precise and robust. Moreover, various analytical methods for estimation of curcumin and cyclosporine alone were reported and in combination with other drugs [8]. However, there is no RPHPLC method for simultaneous estimation of curcumin and cyclosporine in combination along with drug release analysis from the capsule dosage form and the novel method developed in this report is the first of its kind. The developed method is based on the use of a very economical solvent, had short chromatographic time and hence can be performed with ease.

\section{CONCLUSION}

A simple, specific, accurate, precise analytical method was developed. The proposed method presented the ability to separate curcumin and cyclosporine when used in combination in a dosage form using RPHPLC method. It was successfully validated as per ICH-guidelines.
Hence it can be concluded that this method can be easily adopted for routine analysis and quality control of curcumin and cyclosporine fixed-dose combination pharmaceutical dosage forms and API.

\section{AUTHORS CONTRIBUTIONS}

All authors have contributed equally to the manuscript

\section{CONFLICTS OF INTERESTS}

Authors declare no conflicts of interest

\section{REFERENCES}

1. Sharma KA, Agrawal SS, Gupta M. Development and validation of UV spectrophotometric method for the estimation of curcumin in bulk drug and pharmaceutical dosage forms. Inter J Drug Dev Res 2012;4:375-80.

2. Lee KJ, Kim YS, Ma JY. Separation and identification of curcuminoids from Asian turmeric (Curcuma longa L.) using RP-HPLC and LC-MS. Asian J Chem 2013;25:909-12.

3. Pathania V, Gupta AP, Singh B. Improved HPTLC method for determination of curcuminoids from curcuma longa. J Liq Chromatogr Relat Technol 2006;29:877-87.

4. Panigrahi S, Hirlekar R. A new stability-indicating RP-HPLC method for determination of curcumin: an application to the nanoparticulate formulation. Int J Pharm Pharm Sci 2016;8:149-55.

5. Sharma S, Saraogi GK, Kumar V. Development of spectrophotometric methods for simultaneous determination of artesunate and curcumin in a liposomal formulation. Int J Appl Pharm 2015;7:18-21. 
6. Dong WK, Abid MY, Dong XL, John OK, Chul SY, Kwan HC, et al. Development of RP-HPLC method for simultaneous determination of docetaxel and curcumin in rat plasma: validation and stability. Asian J Pharm Sci 2017;12:105-13.

7. Tejavathi DH, Sujatha BH, Kannan R. Estimation of curcuminoids in Curcuma karnatakensis (white turmeric)-an endemic taxon. Asian J Pharm Clin Res 2017;10:360-3.

8. Aziz F, Gupta A, Khan MF. Development and validation of an RP-HPLC method for determination of cyclosporine in the capsule. Indian J Pharm Sci 2010;72:252-5.

9. What role do immunomodulators have in assessing response to curcumin as an add-on therapy for patients with ulcerative colitis? Clin Gastroenterol Hepatol 2016;14:912-9.

10. Validation of analytical procedures: text and methodology Q2(R1), ICH harmonized tripartite guideline, International conference on harmonization of technical requirements for registration of pharmaceuticals for human; 2005.
11. Validation of Compendial Procedures $<1225>$. In: The United States Pharmacopeia/National Formulary, USP32-NF27. Rockville, MD; 2014

12. Xu M, Sun $M$, Qiao H, Ping Q, Elamin ES. Preparation and evaluation of colon adhesive pellets of 5-aminosalicylic acid. Int J Pharm 2014;468:165-71.

13. Sobhita RP, Muthu P, Kadali K. Development and in vitro drug release studies of satranidazole capsules for colon-specific drug delivery. Asian J Pharm Clin Res 2014;7:203-11.

14. Mazumder R, Allamneni Y, Firdous SM, Parya H, Chowdhury AD. Formulation, development and in vitro release effects of ethylcellulose coated pectin microspheres for colon targeting. Asian J Pharm Clin Res 2013;6 Suppl 5:138-44.

15. Singh S, Neelam, Arora S, Singla Y. An overview of the multifaceted significance of Eudragit polymers in drug delivery systems. Asian J Pharm Clin Res 2015;8:1-6. 